\title{
Estrutura e Conteúdos de um Webdocumentário Interativo para o Aprendizado de Neurociências
}

\author{
Marília T. Dutra (IC), Fábio N. Akhras (PQ)
}

\section{Resumo}

O projeto pretende estruturar e produzir conteúdos para um webdocumentário interativo voltado para a promoção do aprendizado e da conscientização social sobre questões de neurociência clínica, especificamente a epilepsia, tanto para pacientes como para familiares, educadores, e o público em geral. O objetivo é atenuar o estigma que normalmente acompanha a doença, utilizando tecnologias de mídia que facilitem e tornem a interação atrativa para o público.

Palavras Chave: webdocumentário, neurociências, aprendizado.

\section{Introdução}

O projeto em questão é parte do CEPID BRAINN - Instituto Brasileiro de Neurociência e Neurotecnologia, no Grupo de Educação e Disseminação do Conhecimento. O objetivo do projeto BRAINN é desenvolver novos métodos e técnicas para melhorar a prevenção, diagnóstico e tratamento de doenças como epilepsia e derrame cerebral, através de meios inovadores. Neste projeto inicia-se a construção de um webdocumentário interativo que seja um desses meios, trabalhando a conscientização social sobre questões da epilepsia, combatendo o estigma que historicamente a acompanha, através de tecnologias de mídia que proporcionem uma interação atrativa para 0 publico.

\section{Resultados e Discussão}

A partir do estudo aprofundado dos conceitos de webdocumentário e divulgação científica, pudemos iniciar a estruturação do produto. Conversamos com a equipe do projeto Questões psicossociais em epilepsia: relatos de pacientes e acompanhantes (VICENTINI, MIN, SPAGNOL, ASSUMPÇÃO, 2014), também parte do CEPID BRAINN, que têm recolhido relatos sobre a qualidade de vida de pacientes; em parceria com esse projeto, decidimos desenvolver uma animação, com um protagonista fictício que seria portador de epilepsia vivendo histórias baseadas nos relatos do projeto. A opção pelo formato vem de uma tentativa de abordagem mais leve do assunto, facilitando o acesso a um público leigo, desmistificando preconceitos e colocando-o em pauta, sem a necessidade de expor o paciente a dividir relatos em frente à câmera. Além das animações, pretendemos adicionar ao webdocumentário pequenos videos com entrevistas informais com pessoas como médicos, educadores, e pessoas próximas a portadores, que possam contribuir com a experiência da convivência e colaborar com o problema da falta de conhecimento sobre o que representam as crises e o quanto afetam a sua rotina (SALGADO, 2003). A interatividade proporcionada pelo webdocumentário virá desde o início: o usuário pode optar por seguir opções programadas de exibição dos vídeos, combinando animações e entrevistas, ou explorálo por conta própria, assistindo na ordem que desejar, de acordo com o tema que lhe interesse.

\section{Conclusões}

A estrutura criada respeita a necessidade da informação sobre a epilepsia, explorando o potencial informativo do webdocumentário para colocá-la em discussão, o que pode fazer uma enorme diferença na vida social de portadores, tendo poder de fazer com que qualquer um com quem tenha contato, reflitam e repensem posturas em relação a ele e a doença.

\section{Agradecimentos}

Gostaria de agradecer ao professor Fábio Akhras pela oportunidade de participar de um projeto tão significativo, à equipe do projeto Questões psicossociais em epilepsia, pelo apoio na construção da estrutura do webdocumentário, e ao Programa Institucional de Bolsas de Iniciação Científica (PIBIC) da Unicamp, e ao Conselho Nacional de Desenvolvimento Científico e Tecnológico (CNPq) pelo financiamento de minha participação no projeto.

SALGADO, Priscila Camile Barioni. A relação entre a percepção de controle de crises e qualidade de vida de adultoscomepilepsia. 2003. 139p. Tese (mestrado) -UNICAMP, Campinas, SP.

VICENTINI, Jéssica Elias, MIN, Li Li, SPAGNOL, Gabriela Salim, e ASSUMPÇÃO, Isilda. Questões psicossociais em epilepsia: relatos de pacientes e acompanhantes. UNICAMP, Campinas, SP. Setembro de 2014. Trabalho ainda não publicado. 